\title{
3T BOLD MRI with low intrascan variability and high reproducibility of limb oxygenation measurements
}

\author{
Erik Hedstrom ${ }^{1,3^{*}}$, Ashish S Patel ${ }^{2,3}$, Tobias Voigt ${ }^{1,4}$, Bijan Modarai ${ }^{2,3}$, Tobias Schaeffter $^{1,3}$, Alberto Smith ${ }^{2,3}$, \\ Eike Nagel ${ }^{1,3}$
}

From 15th Annual SCMR Scientific Sessions

Orlando, FL, USA. 2-5 February 2012

\section{Background}

Current imaging methods, including BOLD MR imaging, cannot reliably quantify muscle oxygenation in patients with limb ischaemia. The BOLD response is complex and measurements have so far been performed in relatively low-resolution EPI-readout images where it may be difficult to exclude oxygenation changes from partial volume effects. The reproducibility of BOLD imaging has been low and consequently its usefulness as a clinical test has been limited. We propose a high-resolution BOLD sequence whereby edge artefacts and vessels may be excluded from measurements, analysed using a Maximum Likelihood Estimate with Rician noise correction, where noise is read in k-space, for a precise and unbiased estimation of $\mathrm{T}^{*}$ from magnitude images. We test the hypothesis that this gives high reproducibility at baseline, and during and after transient ischaemia.

\section{Methods}

The lower limbs of eight volunteers without limb disease (median age 66 \pm 3 yrs) were imaged twice for reproducibility at time intervals between 1 and 190 days at 3T with a 32-channel coil (Philips Achieva, Best, NL). During each scan transient ischaemia was induced by application of a compression cuff around the thigh inflated to suprasystolic pressure for $5 \mathrm{mins}$. The multiecho multi-shot GRE BOLD images (TR 66ms, TE1 4.6 ms, $\triangle$ TE $4.6 \mathrm{~ms}$, 14 echoes, $1535 \mathrm{~Hz} / \mathrm{px}$, FA $20^{\circ}$, FOV $300 \times 150 \mathrm{~mm}$, matrix $256 \times 128$ ) were acquired every $2 \mathrm{~s}$ at baseline and during the dynamic phases of ischaemic response. Data was analysed for early (20s) and late (280s) during cuffing, and for early (20s) and late (315s) after cuff deflation, and interscan reproducibility assessed. Intrascan variability was also determined in an uncuffed population ( $\mathrm{n}=12$; median age $67 \pm 2 \mathrm{yrs}$ ). Regions of interest were drawn around the anterior (ant) and lateral (lat) muscle compartments and around the gastrocnemius (gc) and the soleus (sol) muscles, masking out edge artefacts and vessels.

\section{Results}

Image resolution was superior to standard EPI BOLD (Figure 1). Intrascan variability for each muscle group was: ant $<0.1 \pm 0.5 \mathrm{~ms}$, lat $<0.3 \pm 0.9 \mathrm{~ms}, \mathrm{gc}<0.2 \pm 0.5 \mathrm{~ms}$, and sol $<0.1 \pm 0.6 \mathrm{~ms}$ (all $\mathrm{p}$ values between intrascan time points for each muscle group $=\mathrm{NS}$ ), Figure 2. Interscan reproducibility for baseline was: ant $<1.3 \pm 1.9 \mathrm{~ms}$, lat $<1.7$ $\pm 1.2 \mathrm{~ms}$, gc $<1.0 \pm 1.0 \mathrm{~ms}$, and sol $<0.6 \pm 2.5 \mathrm{~ms}$; for minimum $\mathrm{T} 2 *$ during ischaemia ant $<0.8 \pm 0.2 \mathrm{~ms}$, lat $<0.9 \pm 1.9 \mathrm{~ms}$, gc $<0.7 \pm 1.0 \mathrm{~ms}$, and sol $<2.1 \pm 1.6 \mathrm{~ms}$; for maximum $\mathrm{T} 2$ * early after cuff deflation ant: $<0.2 \pm 1.0 \mathrm{~ms}$, lat: $<3.0$ $\pm 0.3 \mathrm{~ms}$, gc: $<1.0 \pm 1.1 \mathrm{~ms}$, and sol: $<0.9 \pm 0.7 \mathrm{~ms}$; and for T2* late after cuff deflation ant $<0.8 \pm 1.2 \mathrm{~ms}$, lat $<2.4$ $\pm 1.5 \mathrm{~ms}$, gc $<0.9 \pm 0.3 \mathrm{~ms}$, and $\mathrm{sol}<0.9 \pm 0.6 \mathrm{~ms}$ (all $\mathrm{p}=\mathrm{NS}$ ). Compared with baseline, the minimum and maximum T2* values were $-19 \pm 7 \%$ and $1 \pm 7 \%$, respectively.

\section{Conclusions}

The sequence and analysis proposed shows low intrascan variability and high interscan reproducibility for measurement of $\mathrm{T}^{*}$. The technique is therefore well suited for serial assessment of limb muscle oxygenation. 


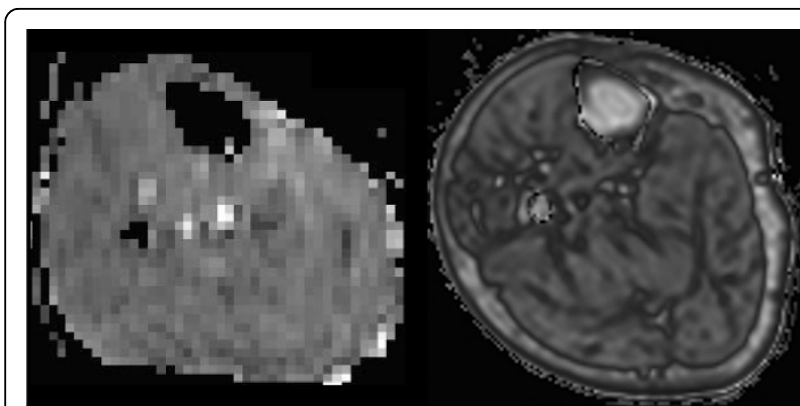

Figure $1 \mathrm{T2}^{*}$ maps by standard EPI BOLD (left) compared with the proposed non-EPI GRE BOLD sequence (right).

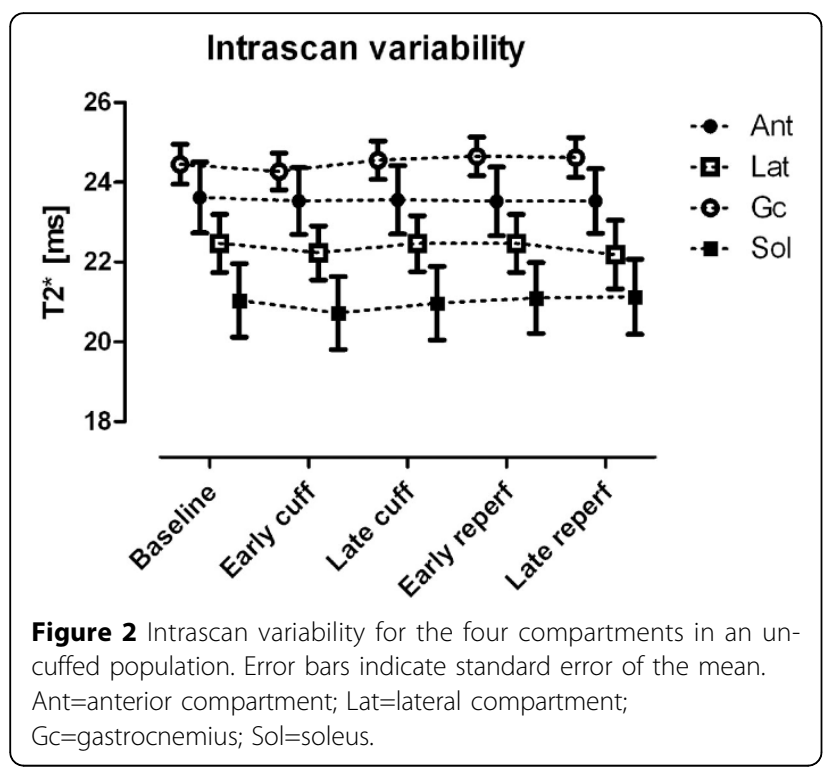

\section{Funding}

British Heart Foundation. The National Institute for Health Research (NIHR) Biomedical Research Centre (BRC) at Guy's and St Thomas' NHS Foundation Trust and King's College London. Lund University Medical Faculty (Stiftelsen Regementsläkaren dr Hartelii stipendiestiftelse) and Lund University Hospital, Sweden. The Foundation BLANCEFLOR Boncompagni-Ludovisi, née Bildt, Sweden. The Swedish societies of Medicine, Cardiology, and Radiology. Covidien.

\section{Author details}

'Division of Imaging Sciences and Biomedical Engineering, Kings College London, London, UK. Academic Department of Surgery, St Thomas' Hospital, Kings College London, London, UK. ${ }^{3}$ BHF Centre of Research Excellence and NIHR Biomedical Research Centre at Guy's and St Thomas' NHS Foundation Trusts and King's College London, London, UK. ${ }^{4}$ Philips Research, Clinical Research Europe, London, UK.

Published: 1 February 2012
doi:10.1186/1532-429X-14-S1-P282

Cite this article as: Hedstrom et al:: 3T BOLD MRI with low intrascan variability and high reproducibility of limb oxygenation measurements. Journal of Cardiovascular Magnetic Resonance 2012 14(Suppl 1):P282.

\section{Submit your next manuscript to BioMed Central} and take full advantage of:

- Convenient online submission

- Thorough peer review

- No space constraints or color figure charges

- Immediate publication on acceptance

- Inclusion in PubMed, CAS, Scopus and Google Scholar

- Research which is freely available for redistribution 